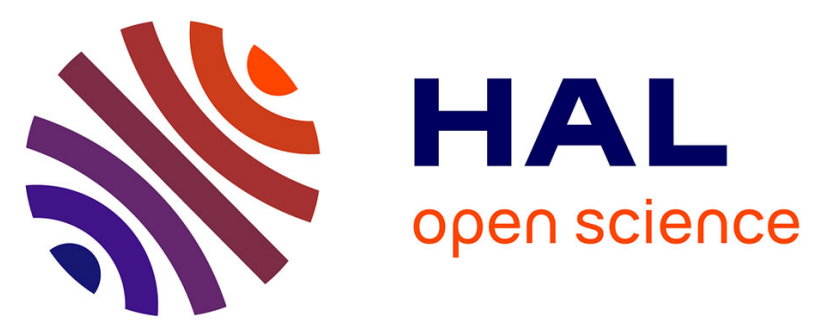

\title{
Age-mediated and environmentally mediated brain and behavior plasticity in the stingless bee Melipona quadrifasciata anthidioides
}

Hudson Tomé, Conrado Rosi-Denadai, Jessica Pimenta, Raul Guedes, Gustavo Martins

\section{To cite this version:}

Hudson Tomé, Conrado Rosi-Denadai, Jessica Pimenta, Raul Guedes, Gustavo Martins. Age-mediated and environmentally mediated brain and behavior plasticity in the stingless bee Melipona quadrifasciata anthidioides . Apidologie, 2014, 45 (5), pp.557-567. 10.1007/s13592-014-0272-7 . hal-01234752

HAL Id: hal-01234752

https://hal.science/hal-01234752

Submitted on 27 Nov 2015

HAL is a multi-disciplinary open access archive for the deposit and dissemination of scientific research documents, whether they are published or not. The documents may come from teaching and research institutions in France or abroad, or from public or private research centers.
L'archive ouverte pluridisciplinaire HAL, est destinée au dépôt et à la diffusion de documents scientifiques de niveau recherche, publiés ou non, émanant des établissements d'enseignement et de recherche français ou étrangers, des laboratoires publics ou privés. 


\title{
Age-mediated and environmentally mediated brain and behavior plasticity in the stingless bee Melipona quadrifasciata anthidioides
}

\author{
Hudson Vaner V. Tomé ${ }^{1}$, Conrado A. Rosi-Denadai ${ }^{1}$, Jessica Fernanda N. Pimenta ${ }^{1}$, \\ Raul Narciso C. Guedes ${ }^{1}$, Gustavo F. Martins ${ }^{2}$ \\ ${ }^{1}$ Departamento de Entomologia, Universidade Federal de Viçosa, Viçosa, Minas Gerais 36570-000, Brazil \\ ${ }^{2}$ Departamento de Biologia Geral, Universidade Federal de Viçosa, Viçosa, Minas Gerais 36570-000, Brazil
}

Received 27 June 2013 - Revised 15 December 2013 - Accepted 17 January 2014

\begin{abstract}
Structural changes in the insect brain related to age and individual experience may underlie the behavioral plasticity that is particularly important in such social insects as bees. This study assessed the influence of age and rearing conditions (field vs laboratory) in mediating changes in the volume of mushroom bodies and antennal lobes in the brains of workers of the native stingless bee Melipona quadrifasciata anthidioides Lepeletier, a pollinator species with small colonies exhibiting high level of sociability and behavioral versatility. Although only age-dependent enlargement was observed in the antennal lobes, significant increase $(21 \%)$ in the neuropils of the mushroom bodies occurred before the foraging age, in contrast to honeybees, and environmental complexity led to a significant increase in both the mushroom body volume and the walking activity. Such differences in the stingless bee M. quadrifasciata anthidioides as compared with the honeybee may assist in relating brain evolution and plasticity with the behavior in these social insects.
\end{abstract}

native stingless bee / walking behavior / mushroom body / native pollinator

\section{INTRODUCTION}

The brain of both vertebrates and invertebrates exhibits a remarkable ability of structural and functional reorganization in response to external stimuli, and the reasons for these neuroanatomical changes are a main focus of modern neurobiology (Kolb and Wishaw 1998; van Praag et al. 2000; Sokolowski 2010). Nervous system remodeling may occur in response to age and environmental signals as a consequence of the individual's experience

Corresponding author: H. Tomé, hudson.tome@ufv.br

Manuscript editor: Bernd Grünewald
(Farris et al. 2001). In addition, an abundance of environmental stimuli, as in social environments, may also induce neuroanatomical changes to affect neurogenesis, dendritic arborization, and learning (Scotto Lomassese et al. 2000; van Praag et al. 2000; Tavosanis 2011). Nonetheless, individual experience and environmental signals are considered preponderant factors of neuroplasticity, altering the dendrite length and size and number of synapses, which has been consistently reported in honeybees (Durst et al. 1994; Kolb and Wishaw 1998; Farris et al. 2001; Tavosanis 2011).

The structural and volume enlargements in the insect brain regions indicate that these changes may also be related to chronological age and behavioral plasticity (Meinertzhagen 
2001; O'Donnell et al. 2004; Fahrbach 2006; Jones et al. 2009). Eusocial bees, such as the honeybee (Apis mellifera L.), can exhibit brain growth in consequence of both experienceexpectant and experience-dependent components (Farhbach et al. 1998). The former refers to the chronological increase of brain regions with age, and the latter refers to such an increase with behavioral changes (or individual experience) (Farhbach et al. 1998). Older honeybees shift nest tasks from simpler ones (e.g., cleaning, nursing, and honeycomb construction) to more complex tasks outside the colony (e.g., foraging), resulting in age polyethism (Winston 1987; Robinson 1992). Therefore, honeybees change from a relatively signal-poor environment (inside the nest) to an external signal-rich environment leading to the increase in brain volume (Withers et al. 1993; Durst et al. 1994; Farris et al. 2001; Krofczik et al. 2008).

Memory retention of multiple signals is crucial for foraging, which also requires the learning of resource location and celestial and terrestrial orientation during long flights (Menzel 2001; Menzel and Giurfa 2006; Srinivasan 2010). Foraging activity coincides with volume increases in certain brain regions when young, inexperienced bees (still living within the colony) are compared with foraging bees (Withers et al. 1993; Farris et al. 2001; Ismail et al. 2006). Nevertheless, older bees prevented from leaving the nest also exhibit neuroanatomical changes, suggesting that the observed brain structural modifications are influenced by both individual experience and by aging (Withers et al. 1995; Fahrbach et al. 1995, 1998; Farris et al. 2001; Fahrbach 2006).

The mushroom bodies of the insect brain are regions of multisensorial integration and are important in memory and learning (Menzel 2001; Menzel and Giurfa 2001, 2006; Heisenberg 2003; Fahrbach 2006; Wessnitzer and Webb 2006). Neuroplasticity occurs in the mushroom bodies as a consequence of aging, experience, and social interactions (Farris et al. 2001; Fahrbach 2006). Interestingly, the mushroom body calyces of the honeybee are larger in foraging workers than in young bees (Withers et al. 1993; Farris et al. 2001), a consequence of increases in dendritic arborization (Fahrbach et al. 1995; Farris et al. 2001). In addition to the mushroom bodies, specific glomeruli of the antennal lobes in some species can also change in volume with age, particularly when the worker bee begins to forage (Withers et al. 1993; Sigg et al. 1997; Morgan et al. 1998; Brown et al. 2002, 2004).

The present study aimed to assess the changes in the brain and behavior of workers of the stingless bee Melipona quadrifasciata anthidioides Lepeletier (Apidae: Meliponinae), a major pollinator in tropical ecosystems, as a function of their age and the environment in which they develop. Colonies of this species are small (300-600 bees), and the workers perform activity within the colonies longer (several days) than the honeybees starting to fly only at advanced age (between 28 and 30 days after emergence). Based on reports for honeybees, an increase in mushroom body volume and increased walking activity was expected with aging, particularly during the foraging age, and increased environmental complexity (Withers et al. 1993; Fahrbach et al. 1998; Farris et al. 2001; Fahrbach 2006; Ismail et al. 2006). However, in contrast to honeybees, the results obtained indicate that increases in neuropils of mushroom bodies of $M$. quadrifascista anthidioides occurred in nurse bees before the stingless bees reached the foraging age.

\section{MATERIAL AND METHODS}

\subsection{Stingless bee colonies}

Five colonies of $M$. quadrifasciata anthidioides were collected in Viçosa County (state of Minas Gerais, Brazil; $20^{\circ} 45^{\prime} \mathrm{S}$ and $42^{\circ} 52^{\prime} \mathrm{W}$ ) and maintained in the Experimental Apiary of the Federal University of Viçosa for subsequent use in the experiments. Although the colonies are currently maintained in the same area, they were originally collected from different fields to allow for representative genetic variability among colonies. 


\subsection{Field-reared bees}

Pupa-containing brood chambers were removed from field nests and maintained under controlled incubators at $28 \pm 2{ }^{\circ} \mathrm{C}, 75 \pm 5 \%$ relative humidity, and $24 \mathrm{~h}$ of darkness until the emergence of adult workers (similar to their natural conditions). Upon emergence, the workers were marked with nontoxic paint of different colors (Brasilux ${ }^{\circledR}$, São Paulo, São Paulo, Brazil) for age monitoring and subsequently returned to the colony of origin. The newly emerged adult worker bees $(<1$ day old) were periodically collected at the ages of 4,8 , and 28 days after emergence, in addition to foraging bees ( $>32$ days old), for histological and behavioral analyses. The bees were collected from the same five nests, each nest corresponding to an independent replicate in each experiment. Although the newly emerged bees ( 4 and 8 days old) are not able to fly and leave the colony, they can perceive (sun) light at the colony entrance.

\subsection{Laboratory-reared bees}

Laboratory-reared bees were obtained as described by Tomé et al. (2012) by removing egg-containing brood chambers from field hives and transferring them to artificial cells filled with $130-\mu \mathrm{L}$ diet (added to $10 \mu \mathrm{L}$ of water), providing sufficient food for full larval development. The artificial cells were constructed with honeybee wax and placed in the wells of polyethylene microplates (24-well plates), which were individually covered with a (honeybee) wax cap. The larval diet was obtained from the same hives as the larvae, and the brood chambers were maintained at $28 \pm 2{ }^{\circ} \mathrm{C}, 90 \pm 5 \%$ relative humidity, and $24 \mathrm{~h}$ of complete darkness until the end of the feeding period. The artificial brood chambers were subsequently transferred to the same conditions as described for the field-reared colonies; the adult bees were marked with nontoxic paint upon emergence and transferred to wood microhives $(10 \times 10 \times 3 \mathrm{~cm})$ in groups of $10 \pm 2$ bees. The adult bees received honey syrup and pollen ad libitum, and newly emerged adult workers ( $<1$ day old) and workers at 4 and 8 days of age were collected for histological and behavioral analyses. The adult workers reared in the laboratory died before reaching an age of 28 days after emergence ( $\sim 15$ days after emergence).

\subsection{Morphometry of mushroom bodies and antennal lobes}

The volumes of the mushroom bodies and antennal lobes of five adult workers, each randomly obtained from a different colony, were measured at newly emerged adult workers, and at 4 and 8 days after emergence for both the field- and lab-reared bees and at 28 days after emergence for the fieldreared bees. The volume of these brain regions were measured in these bees reared either in the laboratory or in the field to represent the distinct social environment in which they were reared. The insects were chilled at $2{ }^{\circ} \mathrm{C}$, and their brains were dissected in insect physiological solution; the tissues were then fixed in $4 \%$ paraformaldehyde in $0.1 \mathrm{M}$ phosphate buffer ( $\mathrm{pH}$ 7.4) for $24 \mathrm{~h}$. The fixed samples were rinsed in $0.1 \mathrm{M}$ phosphate-buffered saline (PBS), dehydrated in an increasing series of ethanol concentrations (70-100 \%), and embedded in JB4 historesin (EMS) according to the manufacturer's instructions. The brains were subjected to serial sectioning $(7-\mu \mathrm{m}-$ thick slices) using a glass knife on an automatic microtome (Leica RM 2255, Leica Microsystems, Wetzlar, Germany). The brain sections were mounted on glass slides and stained with hematoxylin and eosin before photographing using a digital camera (Canon Power Shot A640, Lake Success, NY, USA) coupled to a light microscope (Axioskop 40, Zeiss, Göttingen, Germany). The measurements were performed at each of six-section intervals with the software Image-Pro Plus ${ }^{\mathrm{TM}}$ (MediaCybernetics, Bethesda, MD, USA) following Cavalieri's method (Gundersen and Jemsen 1987; Møller et al. 1990; Withers et al. 1993; Fahrbach et al. 1995; Tomé et al. 2012). For the determination of the volume of the mushroom bodies, the median and lateral calyces and the median and vertical peduncles and lobes were considered; for the volume of the antennal lobes, the total area encompassing all of the glomeruli was considered (Figure 1).

\subsection{Walking behavior}

Behavioral walking bioassays were performed to assess the walking activity of workers at different ages. Each insect was individually transferred to 


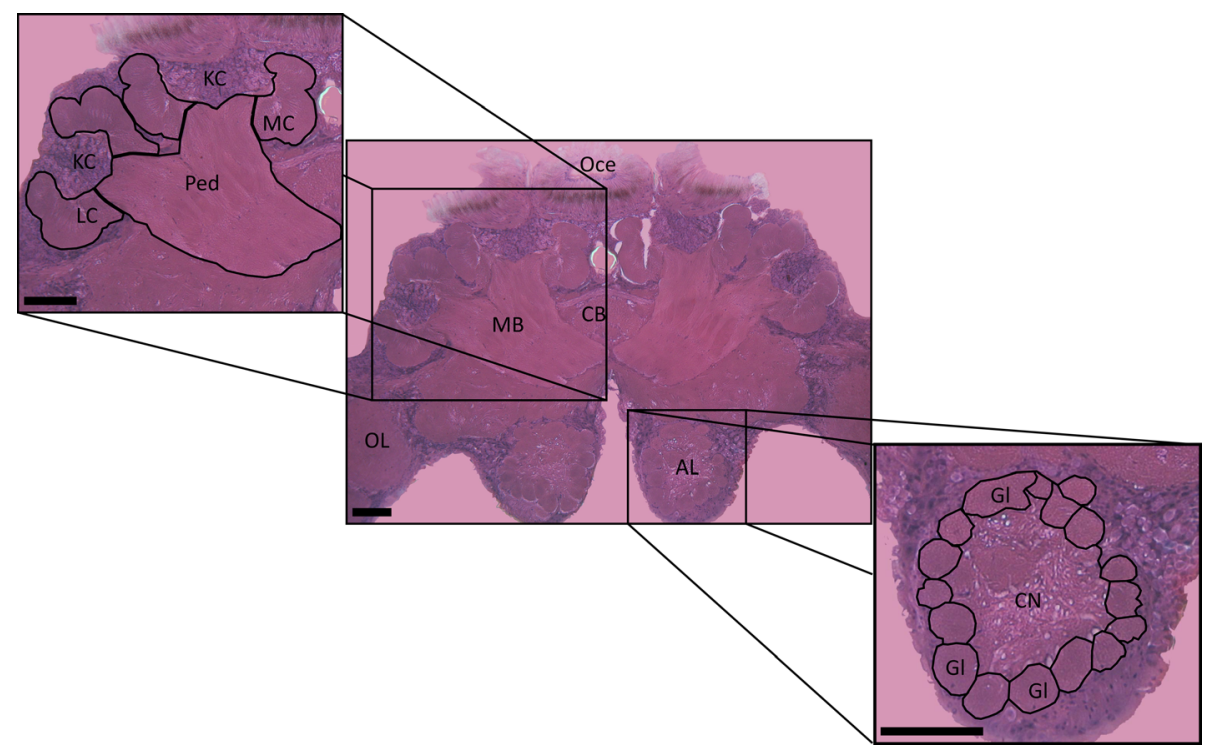

Figure 1 Median transversal section of the brain of a stingless bee (Melipona quadrifasciata anthidioides) worker showing the regions of the mushroom bodies and antennal lobes. Both regions are delimited by black lines at the higher magnification. $M C$ median calyx, $L C$ lateral calyx, $K C$ Kenyon cells, $P e d$ pedunculum, $M B$ mushroom body, Oce oceli, $A L$ antennal lobe, $C N$ central neuropil, $G l$ glomerulus, $O L$ optical lobe, $C B$ central body. Bars $100 \mu \mathrm{m}$

an open petri dish arena $(9-\mathrm{cm}$ diameter and $2-\mathrm{cm}$ high) lined with a filter paper (Whatman no. 1); the inner walls were covered with Teflon ${ }^{\circledR}$ polytetrafluoroethylene (PTFE) (Dupont, Wilmington, DE, USA) to prevent insect escape (the adult workers do not fly at the tested ages). Insect movements were recorded for $10 \mathrm{~min}$ and digitally transferred to a computer using an automated video tracking system equipped with a charge-coupled device (CCD) camera (ViewPoint Life Sciences, Montreal, Canada). The walking parameters recorded were distance walked (centimeters), walking velocity (average) (centimeters/second), and resting time (seconds). The walking behavior was recorded for adult workers immediately after emergence and at 4 and 8 days thereafter (before the workers are able to fly; Waldschmidt and Campos (1997)). The walking bioassays were performed at room temperature with an artificial light, a temperature of $25 \pm 3{ }^{\circ} \mathrm{C}$, and between 2:00 and 6:00 p.m. Twenty-five adult workers of each age and rearing strategy (field or laboratory) were used in the walking bioassays in which each replicate corresponded to the average of five individual bees from each of the five colonies used (i.e., the colonies were the replicates).

\subsection{Statistical analysis}

The results for the volume of the mushroom bodies and antennal lobes of field-reared workers up to 28 days old were subjected to a (linear) regression analysis (PROC REG; SAS Institute 2008), with age as the independent variable and volume (of either mushroom bodies or antennal lobes) as the dependent variable. Student's $t$ tests were used to compare the volumes of the mushroom bodies and antennal lobes of the worker bees reared in the laboratory or field at 1,4 , and 8 days after emergence $(P<0.05)$. The walking behavior data were subjected to repeated measures analyses of variance to test the effect of the rearing environment (field vs laboratory) considering age as pseudoreplicates (in time), and eventual differences in the age intervals were tested by 


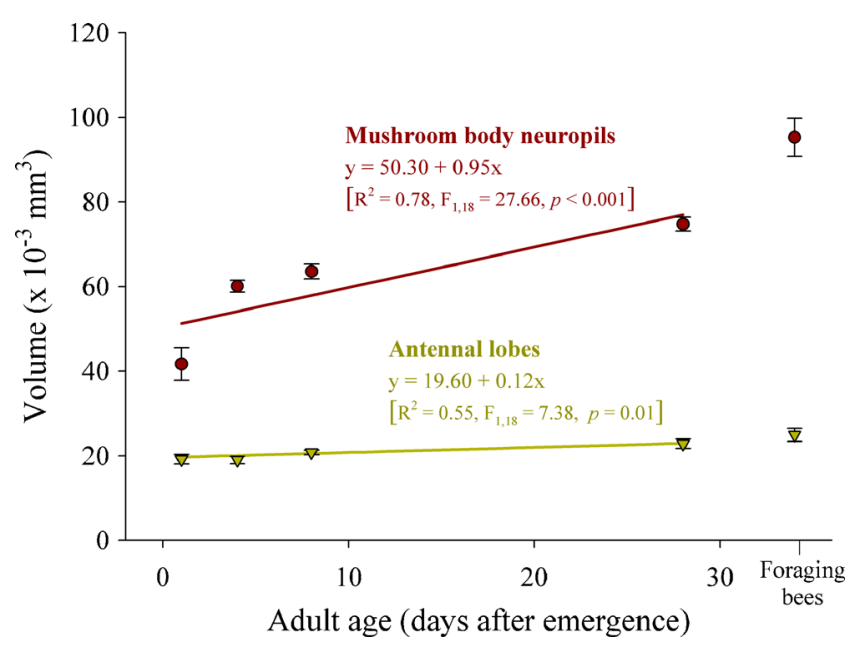

Figure 2 Volume of the mushroom body neuropils and antennal lobes in the brains of stingless bee (Melipona quadrifasciata anthidioides) workers at different ages and reared in the field under natural conditions. The foraging bees were not included in the regression analysis because their exact age was unknown. The symbols represent the means of five replicates, and the vertical bars represent the standard error

Fisher's $F$ test (PROC ANOVA with the PROFILE statement; SAS Institute 2008).

\section{RESULTS}

\subsection{Morphometry of mushroom bodies and antennal lobes}

The volume of both the mushroom bodies and antennal lobes increased with age in the adult workers of the stingless bee $M$. quadrifasciata anthidioides obtained from the field-reared colonies (Figure 2). Such volume increases with age were particularly larger for the mushroom bodies compared to the antennal lobes, with the foraging bees (i.e., over 32 days old) exhibiting $21.2 \%$ higher mushroom body volume than the 28-day-old worker bees (Figure 2).

The laboratory- and field-reared adult worker bees of M. quadrifasciata anthidioides also exhibited significant differences with regard to increases in the mushroom body volume with age (Figure 3). The mushroom body volume was similar in the newly emerged adult workers reared in field and laboratory colonies (38.10土 $\left.10.34 \times 10^{-3} \mathrm{~mm}^{3} ; t_{1,8}=1.12, P=0.29\right)$ but increased to significant levels with aging $\left(t_{1,8}>\right.$ 2.44, $P<0.04$ ) (Figure 3). In contrast, the antennal lobe volume was similar between the laboratory- and field-reared bees $(17.67 \pm 2.67 \times$ $10^{-3} \mathrm{~mm}^{3}$ for newly emerged bees, $19.22 \pm$ $2.10 \times 10^{-3} \mathrm{~mm}^{3}$ for 4-day-old bees, and $20.78 \pm$ $2.86 \times 10^{-3} \mathrm{~mm}^{3}$ for 8 -day-old bees; $t_{1,8}<0.52$, $P>0.61)$.

\subsection{Walking behavior}

Tracks representative of the typical walking behavior of the young adult workers of $M$. quadrifasciata anthidioides are shown in Figure 4. The repeated measures analyses of variance performed for each walking parameter indicated significant differences between the rearing environments (field vs laboratory: $F_{1,38}>11.76, P<0.001$ ), ages (newly emerged, 4 and 8 days old: Wilk's $\gamma>0.33 ; F>35.42$; $\left.d f_{\text {num } / \text { den }}=2 / 36 ; P<0.0001\right)$, and the interaction between these sources of variation (Wilk's $\gamma>$ $\left.0.82 ; F>3.80 ; d f_{\text {num } / \text { den }}=2 / 36 ; P<0.03\right)$. The differences in the walking activity between the field- and laboratory-reared bees increased with 


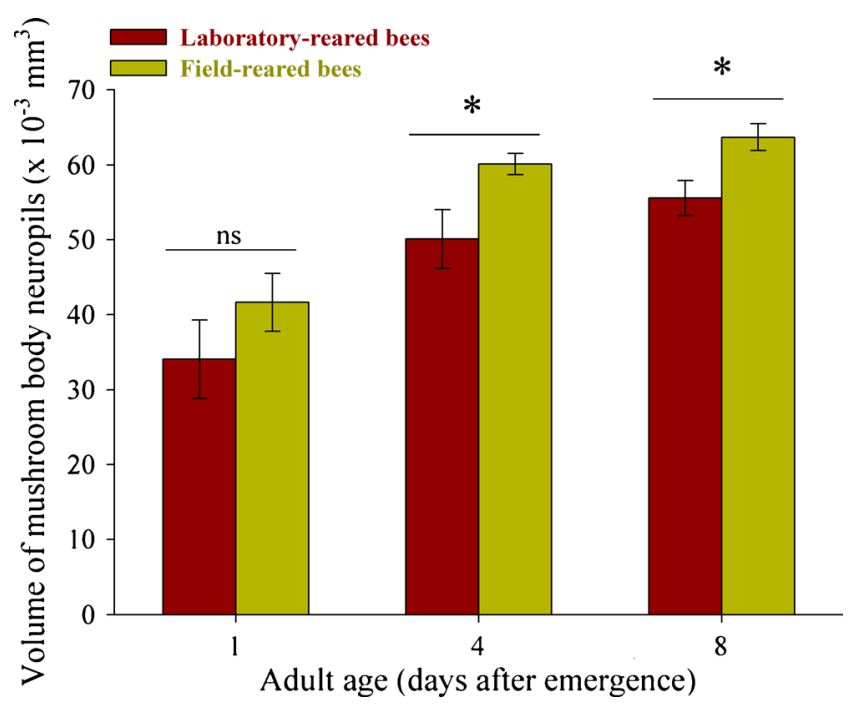

Figure 3 Volume of the mushroom body neuropils in the brains of stingless bee (Melipona quadrifasciata anthidioides) workers at different ages and reared in the field under natural conditions or in the laboratory. The histogram bars represent the means of five replicates, and the vertical bars represent the standard error. The asterisk at the top of the bar indicates the significant differences between the field- and laboratory-reared bees by Student's $t$ test $(P<0.05)$

age, particularly between 4 and 8 days after emergence $\left(F_{1,38}>4.43 ; P<0.03\right)$ (Figure 5). The field-reared adult stingless bees exhibited increased walking activity in comparison with the laboratory-reared bees after reaching 4 days after emergence (Figure 5a, b), and the fieldreared bees began their walking activity soon after emergence, exhibiting a lower resting time (Figure 5c).

\section{DISCUSSION}

Volume changes in brain regions may be related to age and experience and may modulate behavioral changes in both vertebrates and invertebrates (Kolb and Wishaw 1998; Farris et al. 2001; O'Donnell et al. 2004; Fahrbach 2006). Here, we demonstrated for the first time how this process occurs in the stingless bee $M$. quadrifasciata anthidioides native to Brazil. The volumes of the mushroom bodies and antennal lobes in the brain of adult $M$. quadrifasciata anthidioides workers increase with age. In addition, higher mushroom body volume and walking activity (with larger vol- ume and increased activity) were observed for field-reared versus laboratory-reared bees. However, in contrast to the mushroom body of the stingless bees, the volume of the antennal lobes was not affected by the rearing environment.

The increase in the mushroom body volume of newly emerged $M$. quadrifasciata anthidioides workers was significant already in the first 4 days after emergence, with an $80 \%$ increase in volume at 28 days after emergence. These results indicate a high increase in mushroom body volume when the worker bees are still constrained to within-colony tasks, prior to the foraging age. In contrast, the increase in mushroom body volume of honeybee workers occurs mainly at the transition from nursing to foraging activities (Withers et al. 1993; Farris et al. 2001; Fahrbach 2006; Ismail et al. 2006). However, honeybees remain within the hive for only between 1 and 3 weeks, performing various tasks before beginning to forage (Winston 1987); M. quadrifasciata anthidioides workers represent a distinct contrast, as they remain longer within the hive during their adult 


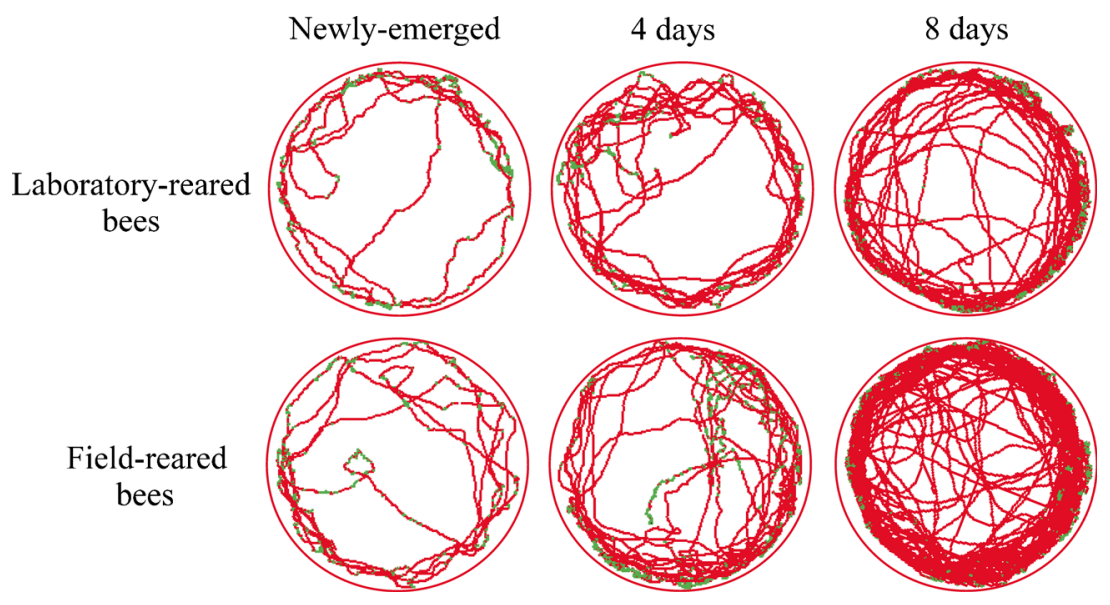

Figure 4 Representative walking tracks exhibiting the movement (for $10 \mathrm{~min}$ ) of individual adult workers (at different ages after emergence) of the stingless bee Melipona quadrifasciata anthidioides reared in the field under natural conditions or in the laboratory. The red tracks indicate high walking velocity, whereas the green tracks indicate low walking velocity (Color figure online)

life ( $\sim 30$ days) before gradually shifting their activities outside the hive (Waldschmidt and Campos 1997; Teixeira et al. 2011).

Workers of $M$. quadrifasciata anthidioides exhibit higher plasticity than honeybee workers with regard to the development of their age-associated tasks, reflecting a higher level of idiosyncrasy that appears to be a consequence of the reduced number of individuals in the small colonies of native stingless bees (Waldschmidt and Campos 1997; Hartfelder et al. 2006). In other words, unlike A. mellifera, which exhibits small colonies and specialized tasks for workers of different ages, workers of $M$. quadrifasciata anthidioides exhibit high worker versatility as a result of the small colony sizes of this species. As the majority of these tasks require learning, the longer permanence of stingless bee workers within the colony (before reaching the foraging age) and the shifts in their within-colony activities may be the main reasons for the higher increase of their mushroom bodies before they begin foraging.

The neural development of worker honeybees is correlated with the age-related tasks performed (Withers et al. 1993; Durst et al. 1994). However, the most relevant changes in the mushroom body volume observed in honeybee workers are mainly associated with the exploration of the external environment and individual experience regarding the multiple environmental signals associated with navigation, orientation, and memory for resource localization (Menzel 2001; Menzel and Giurfa 2006; Fahrbach 2006). Species with less defined age polyethism represent an important contrast, whereby the plasticity of mushroom bodies is likely associated with other factors (Mares et al. 2005). Although the mushroom body plasticity in $M$. quadrifasciata anthidioides workers is evident in 4- and 8day-old nurse bees as a likely consequence of their versatility in activity within the hive before reaching the foraging age, environmental complexity (signal-rich) also appears to play a role in favoring these earlier neuromorphological changes in workers. This is so because the bees maintained in complete dark laboratory conditions exhibited mushroom bodies with smaller neuropils than the field-reared bees.

The social environment is considered to be crucial for the increase of mushroom bodies in honeybees, affecting the behavior and circadian rhythms of locomotory activity in young bees 

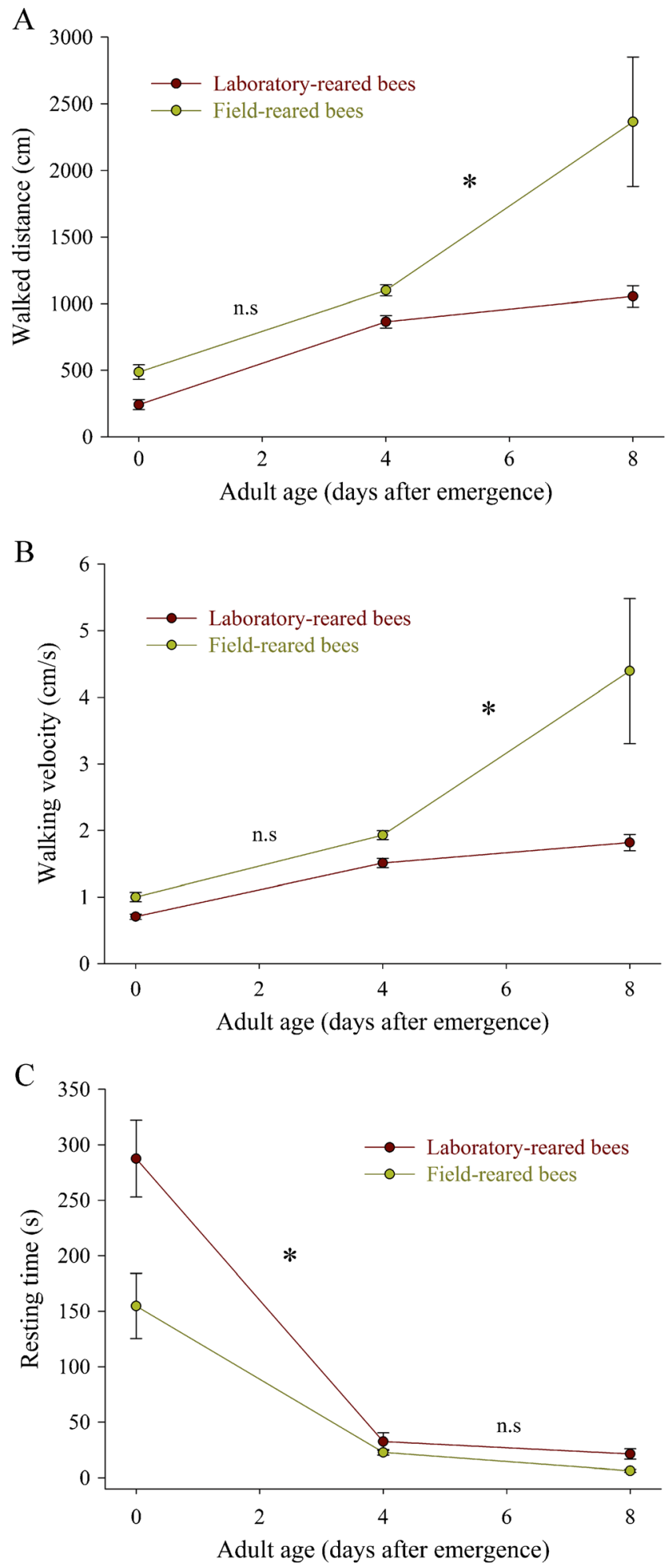
4 Figure 5 Effect of the rearing environment and age after adult emergence on the distance walked (a), walking velocity (b) and resting time (c) of individual adult workers of the stingless bee Melipona quadrifasciata anthidioides reared in the field under natural conditions or in the laboratory. The symbols represent the means of five replicates, and the vertical bars represent the standard error. The asterisk indicates the significant difference in the age interval between the field- and laboratory-reared bees by Fisher's $F$ test $(P<0.05)$

(Maleszka et al. 2009; Smith et al. 2010; Teixeira et al. 2011; Eban-Rothschild et al. 2012). Therefore, the greater walking activity and the increase in mushroom bodies observed in field-reared $M$. quadrifasciata anthidioides are likely consequences of their more social complex environment under natural conditions than in the laboratory (Maleszka et al. 2009). This situation occurs because, in the natural environment, direct contact with the queen, larger number of workers and brood, pheromone exposure, and contact by trophallaxis are more important for communication and colony functioning (Meshi and Bloch 2007). This scenario contributes to enhance individual experiences, consequently leading to neural plasticity and favoring the reported changes in walking activity.

The field-reared worker bees of $M$. quadrifasciata anthidioides exhibited higher walking activity than the laboratory-reared bees and began such activity earlier. Again, these results are the likely consequence of the higher exposure with visual and olfactory signals and social interaction observed in the field-reared bees, which is the result of more complex and diversified environment. Such environmental effects seem so important that apparently compromised the length of survival of the laboratory-reared bees, which did not suffer from nutritional deficiency or disease infection in our study. Honeybees, for instance, exhibit improved memory and learning performance when reared in a colony compared with isolated individuals (Ichikawa and Sasaki 2003; Maleszka et al. 2009). Conspecific interactions also contribute to modulating circadian rhythms in the nurse honeybees (Shemesh et al. 2010; Eban-Rothschild et al. 2012). In $M$. quadrifasciata anthidioides, the contact of nurse bees with foraging bees and the presence of the queen are important for circadian rhythm synchronization and also influence gene expression in young nurse bees to initiate colony activities (Hartfelder et al. 2006; Teixeira et al. 2011). Although we did not explore a broad behavior repertoire in field-reared bees compared with laboratory-reared bees, our results regarding the walking behavior of $M$. quadrifasciata anthidioides suggest that the environmental (social) complexity of the colony may affect the behavioral plasticity of the colony individuals.

In summary, our findings indicate that the neuroanatomical changes of mushroom body volume in $M$. quadrifasciata anthidioides are dependent on age and complexity of the environment stimuli. Signal richness associated with the division of labor within the colony and with the exploration of the external environment also appears important for the plasticity of mushroom bodies of nurse and foraging bees, respectively. This first study on the development of the brain regions of stingless bees and the results obtained provide support for the current model established for social bees in which age and individual experience promote neuroanatomical changes in these insects. Future comparative studies among distinct groups of social bees will be important to elucidate how brain plasticity might contribute to the behavior in these organisms.

\section{ACKNOWLEDGMENTS}

Financial supports provided by the National Council of Scientific and Technological Development (CNPq), the Minas Gerais State Foundation for Research Aid (FAPEMIG), and the CAPES Foundation (Brazilian Ministry of Education) are greatly appreciated and acknowledged here, as were the earlier suggestions provided by Drs. M.A.P. Lima and L.A.O. Campos. The comments and suggestions provided by Prof. B. Grünewald and the three anonymous reviewers were also greatly appreciated. 


\section{Modifications du cerveau en lien avec l'âge et l'environnement et plasticité comportementale chez l'abeille sans aiguillon Melipona quadrifasciata anthidioides}

Comportement de marche / corps pédonculés / pollinisateur indigène / Brésil / Meliponinae

Alters- und erfahrungsabhängige Plastizität des Gehirns und des Verhaltens der stachellosen Biene Melipona quadrifasciata anthidioides

einheimische stachellose Biene / Laufverhalten / Pilzkörper / einheimische Bestäuber

\section{REFERENCES}

Brown, S.M., Napper, R.M., Thompson, C.M., Mercer, A.R. (2002) Stereological analysis reveals striking differences in the structural plasticity of two readily identifiable glomeruli in the antennal lobes of the adult worker honeybee. J. Neurosci. 22, 8514-8522

Brown, S.M., Napper, R.M., Mercer, A.R. (2004) Foraging experience, glomerulus volume, and synapse number: a stereological study of the honey bee antennal lobe. J. Neurobiol. 60, 40-50

Durst, C., Eichmuller, S., Menzel, R. (1994) Development and experience lead to increased volume of subcompartments of the honeybee mushroom body. Behav. Neural Biol. 62, 259-263

Eban-Rothschild, A., Shemesh, Y., Bloch, G. (2012) The colony environment, but not direct contact with conspecifics, influences the development of circadian rhythms in honey bees. J. Biol. Rhythms 27, 217-225

Fahrbach, S.E. (2006) Structure of the mushroom bodies of the insect brain. Annu. Rev. Entomol. 51, 209-232

Fahrbach, S.E., Farris, S.M., Robinson, G.E. (1995) Behavioral development in the honey bee: toward the study of learning under natural conditions. Learn. Mem. 2, 199-224

Farris, S.M., Robinson, G.E., Fahrbach, S.E. (2001) Experience and age-related outgrowth of intrinsic neurons in the mushroom bodies of the adult worker honeybee. J. Neurosci. 21, 6395-6404

Gundersen, H.J.G., Jemsen, E.B. (1987) The efficiency of systematic sampling in stereology and its prediction. J. Microsc. 147, 229-263

Hartfelder, K., Makert, G.R., Judice, C.C., Pereira, G.A.G., Santana, W.C., Dallacqua, R., Bitondi, M.M.G. (2006) Physiological and genetic mechanisms underlying caste development, reproduction and division of labor in stingless bees. Apidologie 37, 144-163

Heisenberg, M. (2003) Mushroom body memoirs: from maps to models. Nature Neurosci. Rev. 4, 266-275

Ichikawa, N., Sasaki, M. (2003) Importance of social stimuli for the development of learning capability in honeybees. Appl. Entomol. Zool. 38, 203-209

Ismail, N., Robinson, G.E., Fahrbach, S.E. (2006) Stimulation of muscarinic receptors mimics experience-dependent plasticity in the honey bee brain. Proc. Natl. Acad. Sci. USA 103, 207-211

Jones, T.A., Donlan, L.A., O'Donnell, S. (2009) Growth and pruning of mushroom body Kenyon cell dendrites during worker behavioral development in the paper wasp, Polybia aequatorialis (Hymenoptera: Vespidae). Neurobiol. Learn. Mem. 92, 485-495

Kolb, B., Wishaw, I.Q. (1998) Brain plasticity and behavior. Annu. Rev. Psychol. 49, 43-64

Krofczik, S., Khojasteh, U., de Ibarra, N.H., Menzel, R. (2008) Adaptation of microglomerular complexes in the honeybee mushroom body lip to manipulations of behavioral maturation and sensory experience. Dev. Neurobiol. 68, 1007-1017

Maleszka, J., Barron, A.B., Helliwell, P.G., Maleska, R. (2009) Effect of age, behaviour and social environment on honey bee brain plasticity. J. Comp. Physiol. A 195, 733-740

Mares, S., Ash, L., Gronenberg, W. (2005) Brain allometry in bumblebee and honey bee workers. Brain Behav. Evol. 66, 50-61

Meinertzhagen, I.A. (2001) Plasticity in the insect nervous system. Adv. Insect Physiol. 28, 84-167

Menzel, R. (2001) Searching for the memory trace in a mini-brain, the honeybee. Learn. Mem. 8, 53-62

Menzel, R., Giurfa, M. (2001) Cognitive architecture of a mini-brain: the honeybee. Trends Cognit. Sci. 5, $62-71$

Menzel, R., Giurfa, M. (2006) Dimensions of cognition in an insect, the honeybee. Behav. Cogn. Neurosci. Rev. 5, 24-40

Meshi, A., Bloch, G. (2007) Monitoring circadian rhythms of individual honey bees in a social environment reveals social influences on postembryonic ontogeny of activity rhythms. J. Biol. Rhythms 22, 343-355

Møller, A., Strange, P., Gundersen, H.J.G. (1990) Efficient estimation of cell volume using the nucleator and disector. J. Microsc. 159, 61-71

Morgan, S.M., Butz-Huryn, V., Downes, S.R., Mercer, A.R. (1998) The effects of queenlessness on the maturation of the honey bee olfactory system. Behav. Brain Res. 91, 115-126

O'Donnell, S., Donlan, L.A., Jones, T.A. (2004) Mushroom body structural change is associated with division of labor in eusocial wasp workers (Polybia aequatorialis, Hymenoptera: Vespidae). Neurosci. Lett. 356, 159-162 
Robinson, G.E. (1992) Regulation of division of labor in insect societies. Annu. Rev. Entomol. 37, 637-665

SAS Institute (2008) SAS/STAT User's Guide v. 8. SAS, Cary, NC, USA.

Scotto Lomassese, S., Strambi, C., Strambi, A., Charpin, P., Augier, R., Aouane, A., Cayre, M. (2000) Influence of environmental stimulation on neurogenesis in the adult insect brain. J. Neurobiol. 45, 162-171

Shemesh, Y., Eban-Rothschild, A.D., Cohen, M., Bloch, G. (2010) Molecular dynamics and social regulation of context-dependent plasticity in the circadian clockwork of the honey bee. J. Neurosci. 30, $12517-12525$

Sigg, D., Thompson, C.M., Mercer, A.R. (1997) Activity-dependent changes to the brain and behavior of the honey bee, Apis mellifera (L). J. Neurosci. 17, 7148-7156

Smith, A.R., Seid, M.A., Jiménez, L.C., Wcislo, W.T. (2010) Socially induced brain development in a facultatively eusocial sweat bee Megalopta genalis (Halictidae). Proc. R. Soc. B 277, 2157-2163

Sokolowski, M.B. (2010) Social interactions in "simple" model systems. Neuron 65, 780-794

Srinivasan, M.V. (2010) Honey bees as a model for vision, perception, and cognition. Annu. Rev. Entomol. 55, 267-284

Tavosanis, G. (2011) Dendritic structural plasticity. Dev. Neurobiol. 72, 73-86
Teixeira, L.V., Waterhouse, J.M., Marques, M.D. (2011) Respiratory rhythms in stingless bee workers: circadian and ultradian components throughout adult development. J. Comp. Physiol. A 197, 361-372

Tomé, H.V.V., Martins, G.F., Lima, M.A.P., Campos, L.A.O., Guedes, R.N.C. (2012) Imidaclopridinduced impairment of mushroom bodies and behavior of the native stingless bee Melipona quadrifasciata anthidioides. PLoS ONE 7(6), e38406. doi:10.1371/journal.pone.0038406

van Praag, H., Kempermann, G., Gage, F.H. (2000) Neural consequences of environmental enrichment. Nat. Rev. Neurosci. 1, 191-8

Waldschmidt, A.M., Campos, L.A.O. (1997) Behavioral plasticity of Melipona quadrifasciata (Hymenoptera: Meliponinae). Rev. Brasil Biol. 58, 25-31

Wessnitzer, J., Webb, B. (2006) Multimodal sensory integration in insects - towards insect brain control architectures. Bioinspir. Biomim. 1, 63-75

Winston, M.L. (1987) The biology of the honey bee. Harvard University, Cambridge, MA, USA

Withers, G.S., Fahrbach, S.E., Robinson, G.E. (1993) Selective neuroanatomical plasticity and division of labour in the honeybee. Nature 364, 238-240

Withers, G.S., Fahrbach, S.E., Robinson, G.E. (1995) Effects of experience and juvenile hormone on the organization of the mushroom bodies of honey bees. J. Neurobiol. 26, 130-144 